\section{Fabrication of bifunctional membrane electrode assemblies for unitised regenerative polymer electrolyte fuel cells}

\section{J. Pettersson, B. Ramsey and D.J. Harrison}

Bifunctional membrane electrode assemblies have been fabricated using a screen printing technique, which demonstrate a repeatable and stable operation to cell current and voltages. This approach lends itself to a rapid, low-cost and repeatable fabrication process for bifunctional catalytic electrodes in polymer electrolyte membrane fuel cells and electrolysers.

Introduction: The conversion and storage of energy with a high efficiency, especially a high specific energy, will be an important factor in future energy storage technologies. The relatively simple possibility to store hydrogen and oxygen with high specific energy combined with high energy conversion efficiency in fuel cells and electrolyser presents an opportunity for the use of polymer electrolyte membrane (PEM) unitised regenerative fuel cell systems (URFCs) as energy storage devices [1,2]. A URFC is an electrochemical cell working both as a fuel cell and as a water electrolyser (see Fig. 1).

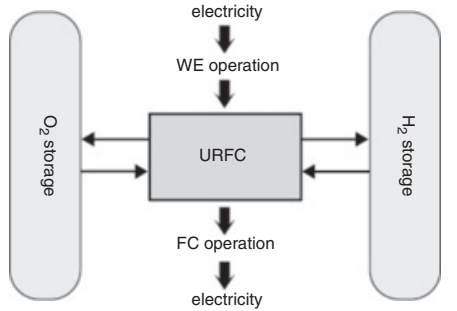

Fig. 1 Concept of unitised regenerative fuel cell (URFC) system

The key technology in the development of a unitised regenerative fuel cell is the bifunctional catalyst and electrode. These can operate in both fuel cell and electrolyser mode. A conventional membrane electrode assembly (MEA) for a PEMFC comprises a Pt/C catalyst layer and a gas diffusion electrode $[4,5]$. However, the conventional membrane electrode assembly is not available for water electrolysis, because the gas diffusion electrode in the PEMFC inhibits diffusion of reactants and products. Thus, most MEAs used in URFCs are constructed of two-layer structure electrodes consisting of membrane and catalyst layers. In addition, most work to date on fabrication of catalysts onto solid polymer electrolytes utilises either a roll-press method or a transfer-print technique [3, 6, 7]. However, in these processes, Nafion membrane has to be temporarily changed to $\mathrm{Na}^{+}$form to avoid swelling during the hot-press transferprinting and Nafion membrane in $\mathrm{Na}^{+}$form possesses higher mechanical strength and temperature range [7]. Other techniques widely used in manufacturing of PEM MEA and promising candidates in the URFC field are screen printing, chemical reduction methods, impregnation techniques and sputter deposition [6,8-11] but these methods need to be developed further to make hydrogen energy systems, based on PEM technology, realistic contestants to modern-day batteries.

The aim of this study was to develop a direct deposition of bifunctional electrocatalyst onto the Nafion membrane for the URFC. For this purpose, we propose a deposition method of catalyst layers on a Nafion membrane by means of screen printing. In the present study, we have developed a bifunctional electrocatalyst layer for URFC systems using a new and improved screen printing method, which omits several process steps compared to other methods. Several MEAs were prepared with the new method and the URFC performance of the prepared bifunctional electrocatalyst layers were evaluated in our single cell PEM URFC system. The composition and content of chosen catalysts were also optimised.

Experiments: Catalytic inks were all manufactured in-house in our ink labs using commercially sourced materials. Commercially available platinum black fine powder, iridium black fine powder and platinum ruthenium (50:50) fine powder (Dart Sensors Ltd, UK) were mixed by the desired ratio. After the catalyst mixture was treated with deionised water to prevent catalyst burning, the mixture, $5 \mathrm{wt} \%$ Nafion solution (Aldrich, $5 \mathrm{wt} \%$ solution) and ethylene glycol (EG) were thoroughly dispersed on a three-roller mill. The obtained
catalyst/Nafion/EG ink was applied to the surface of a pre-treated Nafion 115 [12] by means of screen printing and then hot-pressed at $130^{\circ} \mathrm{C}$ to form the membrane electrode assembly. In this process the Nafion membrane was not required to be substituted to the $\mathrm{Na}^{+}$form, and the membrane was held in position on a vacuum table using a mask with a window cut-out where the ink was screen printed directly onto the surface of the membrane. Several layers may be put down until the desired catalyst loading is achieved. Typical catalyst loadings in these experiments were $3-4 \mathrm{mg} / \mathrm{cm}^{2}$. A titanium fibre substrate was used as gas diffusion backing (GDB) after being dipped in appropriate PTFE emulsion and dried at $110^{\circ} \mathrm{C}$ in air to aid water management of the URFC. The substrate was cut to the same shape as the electrode and pressed against the MEA mechanically in the test cell.

Evaluation of URFC performance was conducted by an in-house designed single cell fixture with an active area of $4 \mathrm{~cm}^{2}$. The MEA and GDB were held in place by two Teflon gaskets clamped between two endplates with machined reservoirs that hold the electrolysis make-up water and the fuel cell reactant gases. Typically, the cell was operated at room temperature and atmospheric pressure. Performance evaluation results were first collected in water electrolysis operation, followed by the fuel cell operation.
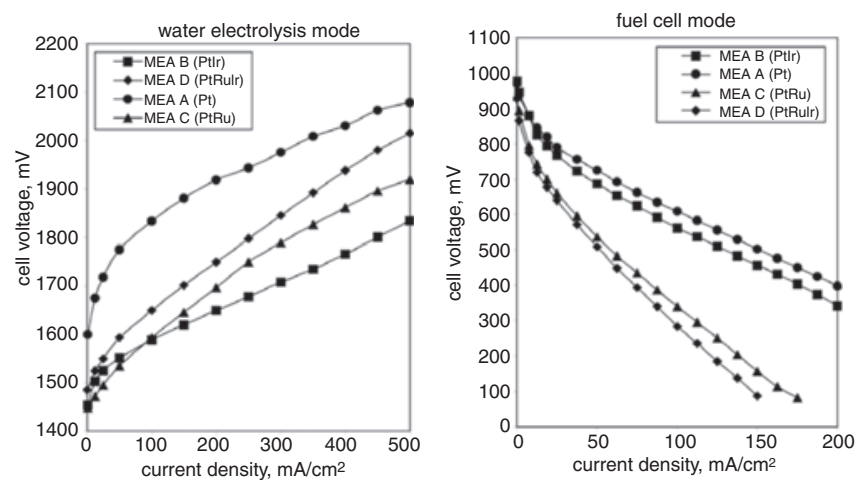

Fig. 2 Terminal voltage against current density curves of URFC with various electrocatalysts

Results: Several kinds of bifunctional electrocatalysts, which have been known as effective for the URFC process, were prepared and tested as shown in Fig. 2. Pt black, PtIr, PtRu and PtRuIr were used as the bifunctional catalysts with loadings of $3-4 \mathrm{mg} / \mathrm{cm}^{2}$. In fuel cell mode, $\mathrm{Pt}$ black had the best performance, showing the highest cell voltage; the addition of other catalyst materials into the printed layer decreased performance in the order of $\mathrm{Pt}$ black $>$ PtIr $>$ PtRu $>$ PtRuIr. In water electrolysis mode, the addition of Ir, Ru and/or both into the printed layer significantly improved performance, lowering the cell voltage compared to Pt black on its own. Consequently, the water electrolysis performance was in the order of PtIr $>$ PtRu $>$ PtRuIr $>$ Pt black. Based on findings, the energy conversion efficiencies for the fuel cell, water electrolysis and combined in the URFC were calculated; the results are shown in Table 1. Efficiencies $\eta_{\mathrm{WE}}, \eta_{\mathrm{FC}}$ and $\eta_{\mathrm{URFC}}$ are given by

$$
\begin{aligned}
& \eta_{\mathrm{WE}}=\Delta H /\left(n F E_{\mathrm{WE}}\right) \\
& \eta_{\mathrm{FC}}=\left(n F E_{\mathrm{FC}}\right) / \Delta H
\end{aligned}
$$

where $n$ is the number of moles of electrons involved in the reaction, $F$ the Faraday constant, $\Delta H$ the enthalpy change of the reaction, and $E_{\mathrm{WE}}$ and $E_{\mathrm{FC}}$ are the terminal voltages for water electrolysis and fuel cell at a given current density. The higher heating value of $\Delta H$ was used in these calculations. The combined URFC cell efficiency can be obtained by multiplying (1) and (2). The efficiency table confirms that the addition of further catalysts in the printed layer results in a contrary effect on fuel cell and water electrolysis performance, showing that optimisation is an important factor for overall performance of URFC systems. The roundtrip efficiency shows that addition of PtIr in the printed electrode structure leads to an overall improved performance in the present URFC system. Yim et al. [13] reported on similar efficiencies with the addition of other catalyst materials into their catalytic layer structure.

The stability and structure of the printed electrode layers are an important factor during cycling of URFCs. Fig. 3 shows the cycle performance of fabricated MEA structures by switching between water electrolysis mode and fuel cell. In fuel cell mode the performance 
deteriorated slightly after the first cycle but stabilised after the third cycle (mass transport overpotentials ignored). The performance loss is most likely a transport problem owing to wetting of cell components in the first water electrolysis cycle as reported by Zhigang et al. [14]. Further testing of the URFC however, showed very little or no deterioration during cycle operation. The cycle of the water electrolysis mode shows stable operation, improving slightly after the first cycle and then maintaining continuous stable performance. The PtRu and PtRuIr on the other hand showed very unstable behaviour during water electrolysis, leading to a serious increase in overpotential, mainly due to anodic corrosion at the oxygen electrode [15].

Table 1: Energy conversion efficiency of URFC system at 50 and $100 \mathrm{~mA} / \mathrm{cm}^{2}$ for various catalysts.

\begin{tabular}{|c|c|c|c|c|}
\hline Current density $\left(\mathrm{mA} / \mathrm{cm}^{2}\right)$ & Catalyst & $\eta_{\mathrm{FC}}(\%)$ & $\eta_{\mathrm{WE}}(\%)$ & $\eta_{\mathrm{URFC}}(\%)$ \\
\hline 50 & $\mathrm{Pt}$ & 49 & 83 & 41 \\
\hline & PrIr & 46 & 95 & 44 \\
\hline & PtRu & 36 & 96 & 35 \\
\hline & PtRuIr & 34 & 93 & 32 \\
\hline 100 & Pt & 43 & 81 & 35 \\
\hline & PrIr & 38 & 93 & 35 \\
\hline & PtRu & 23 & 93 & 21 \\
\hline & PtRuIr & 19 & 90 & 17 \\
\hline
\end{tabular}

$\eta_{\mathrm{WE}}=\Delta H /\left(n F E_{\mathrm{WE}}\right), \eta_{\mathrm{FC}}=\left(n F E_{\mathrm{FC}}\right) / \Delta H, \eta_{\mathrm{URFC}}=\eta_{\mathrm{WE}} \times \eta_{\mathrm{FC}}$
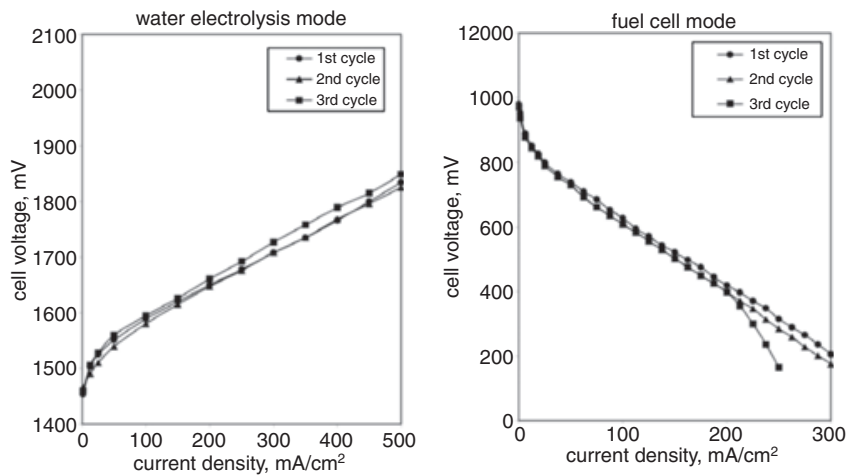

Fig. 3 Cycle performance effect on URFC with catalyst loading $4.0 \mathrm{mg} / \mathrm{cm}^{2}$ PtIr

Conclusion: A fabrication process of bifunctional membrane electrode assemblies for URFCs employing a screen printing procedure has been developed. Electrodes containing suitable bifunctional catalysts have successfully been printed directly onto a Nafion membrane surface. New methods were comparable to previous methods in spite of eliminating the membrane treatment process to
$\mathrm{Na}^{+}$form. Consequently, this manufacturing method leads to a simplified and faster fabrication process.

(C) The Institution of Engineering and Technology 2006

23 August 2006

Electronics Letters online no: 20062620

doi: 10.1049/el:20062620

J. Pettersson, B. Ramsey and D.J. Harrison (Brunel University, School of Engineering and Design, Kingston Lane, Uxbridge, United Kingdom)

E-mail: jonas.pettersson@brunel.ac.uk

\section{References}

1 Baldwin, R., et al.: 'Hydrogen - oxygen proton exchange membrane fuel cells and electrolyzers', J. Power Sources, 1990, 29, pp. 399-412

2 Smith, W.: 'The role of fuel cells in energy storage', J. Power Sources, 2000, 86, pp. 74-83

3 Ioroi, T., et al.: ' $\mathrm{IrO}_{2}$-deposited Pt electrocatalyst for unitized regenerative polymer electrolyte fuel cells", J. Appl. Electrochem., 2001, 31, pp. 1179-1183

4 Jia, N., et al:: 'Modification of Nafion proton exchange membranes to reduce methanol crossover in PEM fuel cells', Electrochem. Solid-State Lett., 2000, 3, pp. 529-531

5 Chun, Y.G., et al.: 'Performance of a polymer electrolyte membrane fuel cell with thin film catalyst electrodes', J. Power Sources, 1998, 71, pp. $174-178$

6 Lee, H., et al.: 'Performance of polypyrrole-impregnated composite electrode for unitized regenerative fuel cell', J. Power Sources, 2004 131, pp. 188-193

7 Wilson, M.S., and Gottesfeld, S.J.: 'Thin-film catalyst layers for polymer electrolyte fuel cell electrodes', J. Appl. Electrochem., 1992, 22, pp. 1-7

8 Kim, C.S., et al.: 'A novel process to fabricate membrane electrode assemblies for proton exchange membrane fuel cells', Int. J. Hydrog. Energy, 1998, 23, pp. 1045-1048

9 Thompson, S.D., et al.: 'Platinum electrodeposition for polymer electrolyte membrane fuel cells', Electrochim. Acta, 2001, 46, pp. 1657-1663

10 Meyers, J.P., and Maynard, H.L.: 'Design considerations for miniaturized PEM fuel cells', J. Power Sources, 2002, 109, pp. 76-88

11 O'Hayre, R., et al.: 'A sharp peak in the performance of sputtered platinum fuel cells at ultra-low platinum loading', J. Power Sources, 2002, 109, pp. 483-493

12 Yoshida, N., et al.: 'Characterization of Flemion membranes for PEFC', Electrochim. Acta, 1998, 43, p. 3749

13 Yim, S.D., et al.: 'Optimization of PtIr electrocatalyst for PEM URFC', Int. J. Hydrog. Energy, 2005, 30, pp. 1345-1350

14 Zhigang, S., et al:: 'Bifunctional electrodes with a thin catalyst layer for "unitized" proton exchange membrane regenerative fuel cell', J. Power Sources, 1999, 79, pp. 82-85

15 Chen, G., et al.: 'Combinatorial discovery of bifunctional oxygen reduction - water oxidation electrocatalysts for regenerative fuel cells', Catalysis Today, 2001, 67, pp. 341-355 